\title{
Diversity Management as a Tool of Managing Intellectual Capital
}

\author{
- Jelínková Eva, Jirincová Milena
}

\begin{abstract}
As a result of various changes in the entrepreneurship environment with the aim to create value and gain sustainable competitive advantage, businesses more often pay attention to soft skills within the management and to intangible assets. The purpose of this paper is to introduce the concept of Intellectual Capital and Diversity Management as a tool for business management and efficient use of Intellectual Capital within a business. After having done research within extant literature about both topics mentioned, there is a practical part of the research which uses two independent questionnaire surveys. One of the questionnaires focuses on the concept of Intellectual Capital and it is still being conducted. This questionnaire uses the first outcomes of the research; the second part deals with the topic of Diversity Management and it was already concluded in 2013. The practical part of the article compares the outcomes of the empiric research in the area of Diversity Management with the results of the research of Intellectual Capital concept. The main question is if the managers of the businesses located in the Czech Republic are aware of the Intellectual Capital concept and whether they understand the importance of its control in comparison to understanding the benefits of Diversity Management which is considered to be a factor with a certain influence on the efficiency of Intellectual Capital. Furthermore, the dependency between the size and sector of a business and its understanding of the Intellectual Capital concept and importance is examined. This is done by means of statistical tools. The results and outcomes of the research are discussed in the final part of the article.
\end{abstract}

Keywords: diversity, intellectual capital, knowledge, management, survey

JEL Classification: M12, M14

\section{INTRODUCTION}

In today's turbulent environment of strong competition and globalization trends it is necessary for businesses to increase their competitiveness by focusing both on soft skills within their management and on their intangible assets. As the recent studies show the focus on hard skills within the management is not sufficient any longer. Generally, in the society there are tendencies to support entrepreneurship competences and activities which then increase economical activities (Prochazkova, 2014; Prochazkova, 2012). Currently, the awareness of human resources importance is growing together with importance of intellectual property which, based on some resources (e.g. Bures, 2007; Krechovska, 2014; Navarro et al., 2013, or Hope \& Fraser 2013), creates the basis for the market value of a business; some studies state the range of $50-90 \%$ which is a significant part and it opens space for further scientific research of this aspect as well as its practical use within the business environment. Inventory and capital can create any value only if they are activated and combined with knowledge. Intellectual Capital is defined as knowledge 
property which can be then converted into a value (Edvinsson \& Sullivan, 1996). Therefore, knowledge plays the main role of Intellectual Capital (Lesser, 2009). Intellectual Capital is a matter for creating and supporting connection among knowledge, expertise, experience and competencies inside and outside an organisation (Bontis \& Cabrita, 2008) with the main goal to create value. The most valuable property of any company, which at the same time has knowledge, expertise, experience and competencies, are its employees. Intellectual Capital is linked to the ability to create and apply the potential of organisation's knowledge (Marr, 2005) and therefore also the potential of its employees' knowledge. To protect and develop knowledge and skills of all employees of whom everybody has a different expectations, different capacity for studying, different way of studying, can be very difficult but also very beneficial at the same time. One of the effective ways of control and active use of different skills of different employees is the concept of Diversity Management which has become very popular recently. In the same way as the concept of Intellectual Capital the Diversity Management belongs among the non-traditional and rather new branches of management which generally reflects the current status of economy and society. For this reason the authors of this article decided to connect those two concepts together into a mutual symbiosis and demonstrate the possibility of their common efficient use in a business environment.

\section{RESEARCH DESIGN}

\subsection{Methodology}

The article is based on the desk research method which uses a research of professional literature in the area of Diversity Management and Intellectual Capital. The empiric part of the article uses the data which was used already for the previously conducted research. An important part of the article is created by a field research especially represented by the outcomes of own questionnaire research by the authors, see below.

The practical part of the research uses two independent questionnaire surveys. One of the questionnaires focuses on the concept of Intellectual Capital and it is still running. This questionnaire uses the first outcomes of the research; the second part dealt with the topic of Diversity Management and it was concluded in 2013. The already concluded research dealt with the topic of Diversity and Diversity Management and its understanding by various organisations in the Czech Republic. This research will mention the main outcomes also based on the previously published articles Egerova and Jirincova (2014) and Egerova, Jirincova, Lancaric and Savov (2013). The second recent research is focused on use of Intellectual Capital by the organisations in the Czech Republic.

Both researches chose to question representatives of various organisations within the Czech Republic as their respondents; the selected respondents are managing employees on the top level of management. They were selected with regard to the complexity and strategic level of the topic. The research in the area of the Intellectual Capital is only at its beginning and a piloting questioning was conducted so far 71 respondents (organisations). The distribution of the questionnaires is performed in their paper form so that the highest possible number of returned questionnaires is assured. The questionnaire distribution in the area of diversity was conducted 
in an electronic form $(2012-2013)$ and a total number of returned questionnaires was 200 from all selected respondents (organisations).

\subsection{Research Goals}

The aim of this research is to follow the already conducted research in the area of Diversity where the individual organisations clearly showed their interest and positive approach towards the diversity control and using of its benefits. The researchers now aim to find out whether they share these ideas and positive approach also towards the concept of Intellectual Capital. The main question is whether the organisations are familiar with the concept of IC and whether they understand its importance in the same level as it was shown for the benefits of Diversity. Diversity Management in our understanding is a factor which carries the potential to influence the quality of Intellectual Capital in an organisation and therefore its understanding should be on a similar level based on the opinion of the authors. First, the aim of the article is to create a theoretical process by means of a literature research which will be used later as a basis for the practical part of the research. The already conducted research in the area of Diversity Management will be only partially mentioned by the article as it focuses on the notion of Intellectual Capital where there is a completely new research being conducted only at its beginning and therefore no results have been published yet.

\subsection{Instruments and Procedures}

For the needs of this article the method of induction and deduction is used, furthermore the method of the desk research of extant literary resources, the method of field research is represented by a questionnaire research, and a partial comparison of the outcomes of independent researches of both authors. For various calculations the methods such as Cronbach's Alpha, basic descriptive statistics, box diagram, Kolmogorov-Smirnov test, Shapiro-Wilk test, Levene test and nonparametric Kruskal-Wallis test by means of the Statistica software are used.

\section{THEORETICAL FRAMEWORK}

\subsection{Intellectual Capital and its Significance for Businesses}

Stewart (2010) defines Intellectual Capital as an intellectual material - knowledge, information, intellectual property, experience - which can be put into use to create wealth. Intellectual Capital is described as a packaged useful knowledge. For Armstrong (2007) means Intellectual Capital a supply and flow of knowledge which the organisation can use. Bontis and Cabrita (2008) decompose Intellectual Capital into three dimensions - the dimension of human capital, structural capital and relational capital. The value creation depends on the effective combination and interaction of those mentioned dimensions. Davies and Magowan (2002) claim that Intellectual Capital is created by exchange and combination of knowledge and those are enabled, among other factors, also by social relationships. Bontis states two mechanisms which are the driving forces and influence Intellectual Capital, they are trust and culture. These two mechanisms create the individual dimensions of Intellectual Capital; they affect the interaction of the dimensions and creation of business value (Bontis, 1999). Knowledge creates a basis of all the dimensions of Intellectual Capital. 
The particular human capital of an individual is characterized as a combination of genetically inherited characteristics, education, experience and attitudes towards life and business (Hudson, 1993). Relational capital is created by knowledge which is anchored in the relationships with customers, suppliers and other stakeholders. Structural capital provides tools (information systems, processes, databases, etc.) which enable to move the knowledge through the process towards the customers to create value. "Organizational knowledge is at the crux of sustainable competitive advantage" (Bontis, 1999, p. 271). The fundamental carriers of the knowledge are people. Human capital is considered to be the primary element of Intellectual Capital and the most important source of any competitive advantage. (Bontis \& Cabrita, 2008) Sveiby in the concept of intangible assets emphasises the fact that people are the only real agents of business and the other agents - tangible assets as well as knowledge - are the results of work of people which depends on knowledge and competences of employees (Sveiby, 1997). Diversity Management can be used to gain high-quality structure of employees, innovative business culture and working environment which respects differences and develops knowledge, expertise, experience and competencies of employees.

\subsection{Diversity Management and its Benefits}

According to Hubbard (2004, p. 27) Diversity Management is defined as "the process of planning for, organizing, directing, and supporting collective mixtures in that way which adds a measurable difference to organizational performance“. Diversity Management is not a clearly limited notion and it can include a wide range of various aspects. Hubbard (2004) divides it into two dimensions - a primary dimension (age, gender, ethnicity, mental and physical abilities and sexual orientation) and a secondary dimension (as for example religion, education, family status, income, location etc.).

In the Czech Republic there are mainly the aspects of gender, age, education, mental and physical skills important for businesses, nevertheless, the aspect of nationality becomes more and more important recently (Jirincova, 2011). It is not always possible to fathom all aspects of diversity either in the practical operation of businesses or in the scientific research. Most of the diversity aspects can be followed and controlled within a company in that way that they bring required benefit with regard to efficiency of individuals, teams and all employees. (Hubbard, 2011, EC. The Costs and Benefits of Diversity, 2003) To implement Diversity Management it is first necessary to define the diversity and choose the approach which will be put into practice by the company. It is also crucial to consider whether in this particular environment, branch or situation Diversity Management is or is not desirable.

Diversity ranks among the so called intangible assets of a business and it is therefore abstract in the same way as Intellectual Capital. The difference in comparison to tangible assets is summarised by Kaplan and Norton (2004) who claim that value creation by means of intangible assets is indirect and it is a result of interconnected relationships, causes and consequences. Intangible assets are very often linked to tangible assets and they do not create value on their own. There are three main resources of creation of intangible assets according to Kaplan and Norton (2004) and those are human capital, information capital and organisational capital. Human capital includes skills, talent, values and important knowledge of employees which strongly affects the efficiency of a business although those people are not owned by the company and therefore 
cannot be force to use those assets. Authors such as Esty (1995), Thiederman (2008), Thomas (2006), or the materials by European Commission (EC, Diversity Management, 2007) mention various benefits which stem from using the concept of Diversity Management. Among the main benefits of Diversity Management there are attracting, recruiting and retaining of best talents, increasing of creativity/innovation, increasing of client loyalty, increasing of company profits, access to new markets or increasing of brand value etc., according to the SMEs in the European Union (EC. Continuing the Diversity Journey, 2008).

\subsection{Diversity Management as a Possible Contribution to Intellectual Capital}

For the purposes of this article it is necessary to mention apart from the important benefit of increasing of business efficiency, the benefits of Diversity Management in the area of Intellectual Capital, such as creation of a rich talent pool and acquisition of best talents with a wide range of knowledge, increasing of creativity among employees, support of innovations, strengthening of cultural values of the organisation, increase of know-how and many others.

Figure 1 demonstrates those benefits of Diversity Management and their correspondence with one entire area of Intellectual Capital which deals with Human Capital but also with most of the aspects of Structural and Relational Capital.

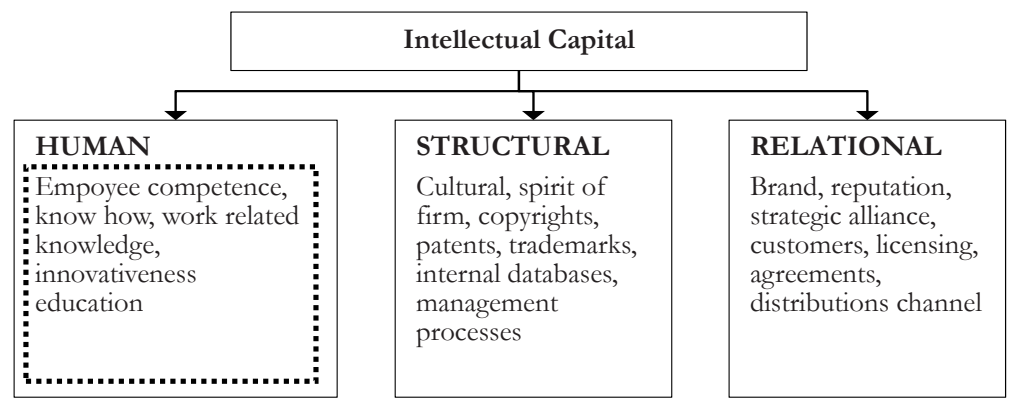

Fig. 1 - Content of Intellectual Capital and the Impact of Diversity Management on it. Source: Intellectual Capital Reporting, 2014.

As we could see in the previous text, there are many benefits which Diversity Management can bring to an organization and most of these benefits are connected to Intellectual Capital and its quality. "Most successful diversity initiatives result in some intangible benefits. Intangible benefits are those positive results that either cannot be converted into monetary values or would involve too much time or expense in the conversion to be worth the effort. The range of intangible outcomes is practically limitless" (Hubbard, 2011, p.102). Moreover, Hubbard (2011) summarizes some typical intangible variables linked with diversity as it is obvious in the Tab. 1. There is also visible the strong connection to the concept of Intellectual Capital. 
Tab. 1 - Typical Intangible Variables Linked with Diversity. Source: Hubbard, 2011, p.103

\begin{tabular}{|c|c|}
\hline Attitude Survey Data & Employee Transfers \\
Organizational Commitment & Customer Satisfaction Survey Data \\
Climate Survey Data & Customer Complaints \\
Employee Complaints & Customer Response Time \\
Grievances & Teamwork \\
Stress Reduction & Cooperation \\
Employee Turnover & Conflict \\
Employee Absenteeism & Decisiveness \\
Employee Tardiness & Communication \\
\hline
\end{tabular}

\section{QUESTIONNAIRE SURVEY}

\subsection{Sample Characteristics and Questionnaire Design}

The questionnaire research in the area of Diversity Management which was already conducted and which will be partially used for comparison purposes with the newly acquired outcomes was conducted in 2012 - 2013 via a questionnaire in Google Docs. The questionnaire consisted of identification questions and of three separate parts - an area of inclusion and justice, implementation, and Diversity Management benefits. There were 355 respondents active within the Czech and Slovakian Republic. In this article the authors will deal only with outcomes related to the situation in the Czech Republic, namely with 135 organisations which are active in the Czech Republic. The questionnaire research was used for organisations which varied in size, sectors and type. The answers of the questionnaire respondents were evaluated and assessed by means of the Likert Scale (1-7) as it was previously used for the research regarding Intellectual Capital.

The newly commenced research in the area of Intellectual Capital was participated by 71 organisations from the Czech Republic, mostly from the Pilsen Region, from which 50 questionnaires were chosen as representative and fully completed for the purposes of the first pilot assessment. Organisations (further used as respondents) are active mainly in the area of processing industry (32\%). Other industrial branches are only exceptional and almost equal in their representation in the research. Mostly limited companies (60\%) and join stock companies (32\%) are represented in the research. Regarding the size of the organisations the research was aimed at medium and large businesses and therefore they create the largest share of all respondents (medium businesses $50 \%$, large businesses $40 \%$ ).

These organisations replied to questions stated in the questionnaire in three parts. The first part of the questionnaire researched the basic background and characteristics of the respondents; the second part of the questionnaire was focused on Intellectual Capital and its elements within the organisations, the third part is an additional section and it questions basic financial indicators such as assets, economical results, own capital, turnover and etc. 
The reliability of the used tool can be considered as good or even excellent as the calculated Cronbach's Alpha indicator shows the value of 0, 8554. (Own processing, STATISTICA, 2015) Generally, the Cronbach's Alpha is used to measure internal consistency of a scale. It ranges from 0 for a completely unreliable test to 1 for a completely reliable test. Most statisticians state that the correct value we need for a questionnaire or a measure tool to be reliable is the value of 0.7 or higher (Brownlow, 2004).

In the following text the authors focus on the examining of first two questions of the questionnaire which try to find out about the respondents' awareness of the notion of IC and the level of understanding of its importance so that it creates an introduction for a future research which will deal with the use of Intellectual Capital in the organisations in the Czech Republic.

\subsection{Awareness and Importance of Intellectual Capital and Diversity Management within Organizations}

Statement Nr. 1 of the questionnaire: "I am familiar with the notion of Intellectual Capital."

Statement Nr. 2 of the questionnaire: "Our company understands the importance of management of Intellectual Capital."

Both these questions were evaluated within the scale from 1 to 7 , where the value 1 means complete disagreement and the value 7 represents complete agreement of a respondent with the particular statement. In the following Tab. 2 and in the connected box diagram in the Fig.2., the basic characteristics of the answers for both statements given above can be seen, namely it is the average value, the maximum and the minimum value and a standard deviation. It is clear that the average value of the answers is slightly higher (therefore more positive) for the Statement Nr.2 and also there is a smaller diversion in the answers than in case of the Statement Nr.1. This can be interpreted as a statistically higher level of agreement in the opinion of the respondents in the area of significance of Intellectual Capital.

Tab. 2 - The descriptive statistics regarding the answers related to Awareness and Importance questions. Source: Own processing at STATISTICA, 2015

\begin{tabular}{|l|c|c|c|c|c|}
\hline \multirow{2}{*}{ Variable } & \multicolumn{4}{|c|}{ Descriptive Statistics } \\
\cline { 2 - 6 } & $\mathrm{N}$ & Mean & Minimum & Maximum & St.Dev. \\
\hline Awareness & 50 & 5,420000 & 1,000000 & 7,000000 & 1,738989 \\
\hline Importance & 50 & 5,500000 & 1,000000 & 7,000000 & 1,606746 \\
\hline
\end{tabular}




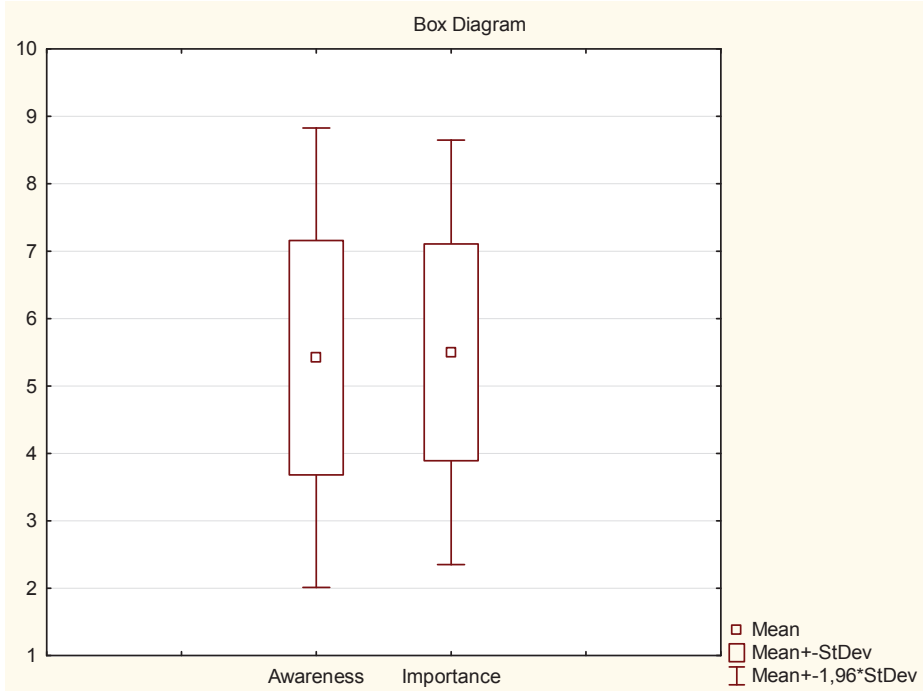

Fig. 2 - The Box Diagram of answers related to Awareness and Importance questions.

Source: Own processing at STATISTICA, 2015

Based on the average values for various business sizes only (see Tab. 3) it can be said that the answers do not differ with regard to the business size. There is a higher awareness of Intellectual Capital among larger businesses, smaller awareness was shown by medium and small businesses.

Tab. 3 - Awareness and Independence of Intellectual Capital depending on Size. Source: Own processing, 2015

\begin{tabular}{|c|c|c|c|c|c|}
\hline \multicolumn{3}{|c|}{ Av. Awareness } & \multicolumn{3}{c|}{ Av. Importance } \\
\hline Small & Medium & Large & Small & Medium & Large \\
\hline 5,4 & 5,36 & 5,5 & 5,4 & 5,48 & 5,55 \\
\hline
\end{tabular}

Nevertheless, the difference is not considerably deviating. Generally, the respondents replied positively with regard to awareness of Intellectual Capital. This notion is therefore no longer completely unknown to them. The importance of Intellectual Capital (see Chapter 4.4) was evaluated mostly positively too and in this case too there are no significant differences in the answers provided by respondents which could be related to the size of a particular business. In the same way, the results of individual industrial branches can be summarized as also there were no big differences in case of awareness of Intellectual Capital or understanding of its significance. Since the Tab. 3 demonstrating average values for all answers for individual sectors would be too large, it is not provided here. 


\subsection{Awareness, Dependency of Answers to Statement Nr.1 on a Particular Business Size and a Sector}

This chapter of the article examines the dependency of awareness of Intellectual Capital on the size of a particular business and a sector of respondents. As a source of fundamental data the Statement Nr. 1 is used: "I am familiar with the notion of Intellectual Capital." The Kolmogorov-Smirnov test as well as the Shapiro-Wilk test of normality proved that data is from normally distributed population and the Levene test of equality of variances did not approve the homoscedasticity, therefore the Kruskal-Wallis test was used. There were the following statistical hypotheses stated regarding the Statement Nr.1 and the factor of a particular business size:

\section{$H_{0}$ : The size of a business has no effect on the awareness of Intellectual Capital. \\ $H_{1}$ : The size of a business has a certain effect on the awareness of Intellectual Capital.}

In the same way, similar hypotheses were set regarding the sector of a particular business:

$H_{0}$ : The branch of a business has no effect on the awareness of Intellectual Capital.

$H_{1}$ : The branch of a business has a certain effect on the awareness of Intellectual Capital.

The following two tables (see Tab. 4 and Tab. 5) show the outcomes of the Statistica programme and they summarize the results of the Kruskal-Wallisova test. In both cases the results reflect the expectations that the $\mathrm{H}_{0}$ cannot be denied and therefore it cannot be said that the size of a business or the branch have a statistically significant influence on the answers of the respondents with regard to their opinions on awareness of Intellectual Capital.

Tab. 4 - Kruskal-Wallis test, Awareness and Size (Small, Medium, Large), Source: Own processing at STATISTICA, 2015

\begin{tabular}{|l|c|c|c|c|}
\hline & \multicolumn{4}{|l|}{$\begin{array}{l}\text { Kruskal-Wal lis ANOVA ; Awareness } \\
\text { Independent : Size } \\
\text { Kruskal-Wal lis test: } \mathrm{H}(2, \mathrm{~N}=50)=, 2049252 \mathrm{p}=, 9026\end{array}$} \\
\hline $\begin{array}{l}\text { Dependent: } \\
\text { Awareness }\end{array}$ & Code & $\begin{array}{c}\text { Number of } \\
\text { Valid }\end{array}$ & Sum of Order & Av. Order \\
\hline S & 104 & 5 & 115,5000 & 23,10000 \\
\hline M & 105 & 25 & 634,5000 & 25,38000 \\
\hline L & 106 & 20 & 525,0000 & 26,25000 \\
\hline
\end{tabular}


Tab. 5 - Kruskal-Wallis test, Awareness and Sector, Source: Own processing at STATISTICA, 2015

\begin{tabular}{|l|c|c|c|c|}
\hline \multirow{2}{*}{} & \multicolumn{4}{|l|}{$\begin{array}{l}\text { Kruskal -Wall is ANOVA; Awareness } \\
\text { Independent : Sector } \\
\text { Kruskal -Wall is test: H (12, N=50)=14,70586 p =,2579 }\end{array}$} \\
\hline $\begin{array}{l}\text { Dependent: } \\
\text { Awareness }\end{array}$ & Code & $\begin{array}{c}\text { Number of } \\
\text { Valid }\end{array}$ & Sum of Order & Av. Order \\
\hline S & 101 & 6 & 191,0000 & 31,83333 \\
\hline G & 102 & 7 & 155,5000 & 22,21429 \\
\hline H & 103 & 3 & 29,0000 & 9,66667 \\
\hline C & 104 & 16 & 441,0000 & 27,56250 \\
\hline F & 105 & 4 & 89,0000 & 22,25000 \\
\hline I & 106 & 1 & 26,5000 & 26,50000 \\
\hline J & 107 & 4 & 81,5000 & 20,37500 \\
\hline A & 108 & 3 & 95,0000 & 31,66667 \\
\hline E & 109 & 2 & 36,5000 & 18,25000 \\
\hline D & 110 & 1 & 42,5000 & 42,50000 \\
\hline Q & 112 & 1 & 2,5000 & 2,50000 \\
\hline M & 113 & 1 & 42,5000 & 42,50000 \\
\hline O & 1 & 42,5000 & 42,50000 \\
\hline
\end{tabular}

(S - Another, G - Wholesale and Retail, H - Transport and Storage, C - Manufacturing, F - Building, I - Accommodation and Catering, J - Information and Communication Activities, A - Agriculture, Forestry, Fishery, E - Water Sector, D - Electricity and Gas, Q - Health and Social Care, M - Research and Technical Activities, $\mathrm{O}-$ Public Administration and Defence)

\subsection{Importance, Dependency of Answers to Statement Nr.2 on a Particular Business Size and a Sector}

To examine the dependency of understanding the importance of Intellectual Capital with regard to the size of a particular business and a sector, the Statement Nr.2 was used: "Our company understands the importance of management of Intellectual Capital." As the evaluation method the Kruskal-Wallis test was used again as the same conditions apply to the researched data - a normally distributed population featuring heteroscedasticity. There were the following statistical hypotheses stated regarding the Statement Nr.2 and the factor of a business size:

$H_{0}$ : The size of a business has no effect on the understanding of importance of Intellectual Capital.

$H_{1}$ : The size of a business has a certain effect on the understanding of importance of Intellectual Capital.

In the same way, similar hypotheses were set regarding the sector of a particular business:

$H_{0}$ : The branch of a business has no effect on the understanding of importance of Intellectual Capital.

$H_{1}$ : The branch of a business has a certain effect on the understanding of importance of Intellectual Capital.

As expected, the following tables (Tab. 6 and Tab. 7) did not confirm any statistically significant differences among the answers in dependency either on size or sector of a business. 
Tab. 6 - Kruskal-Wallis test, Importance and Size (Small, Medium, Large), Source: Own processing at STATISTICA, 2015

\begin{tabular}{|l|c|c|c|c|}
\hline & \multicolumn{4}{|l|}{$\begin{array}{l}\text { Kruskal-Wal lis ANOVA; Importance } \\
\text { Independent : Size } \\
\text { Kruskal-Wal lis test: } \mathrm{H}(2, \mathrm{~N}=50)=, 1013724 \mathrm{p}=, 9506\end{array}$} \\
\hline $\begin{array}{l}\text { Dependent: } \\
\text { Importance }\end{array}$ & Code & $\begin{array}{l}\text { Number of } \\
\text { Valid }\end{array}$ & Sum of Order & Av. Order \\
\hline M & 104 & 25 & 642,0000 & 25,68000 \\
\hline S & 105 & 5 & 118,0000 & 23,60000 \\
\hline L & 107 & 20 & 515,0000 & 25,75000 \\
\hline
\end{tabular}

Tab. 7 - Kruskal-Wallis test, Importance and Sector, Source: Own processing at STATISTICA, 2015

\begin{tabular}{|l|c|c|c|c|}
\hline & \multicolumn{4}{|l|}{$\begin{array}{l}\text { Kruskal -Wall is ANOVA: Importance } \\
\text { Independent : Sector } \\
\text { Kruskal -Wall is test: H (12, N= 50) }\end{array}$} \\
\hline $\begin{array}{l}\text { Dependent: } \\
\text { Importance }\end{array}$ & Code & $\begin{array}{l}\text { Number of } \\
\text { Valid }\end{array}$ & Sum of Order & Av. Order \\
\hline S & 101 & 6 & 182,0000 & 30,33333 \\
\hline G & 102 & 7 & 206,0000 & 29,42857 \\
\hline H & 103 & 3 & 26,5000 & 8,83333 \\
\hline C & 104 & 16 & 430,0000 & 26,87500 \\
\hline F & 105 & 4 & 94,0000 & 23,50000 \\
\hline I & 106 & 1 & 27,0000 & 27,0000 \\
\hline J & 107 & 4 & 100,5000 & 25,12500 \\
\hline A & 108 & 3 & 59,5000 & 19,83333 \\
\hline E & 109 & 2 & 35,5000 & 17,75000 \\
\hline D & 110 & 1 & 42,5000 & 42,5000 \\
\hline Q & 111 & 1 & 2,0000 & 2,0000 \\
\hline M & 112 & 1 & 42,5000 & 42,5000 \\
\hline O & 113 & 1 & 27,0000 & 27,0000 \\
\hline
\end{tabular}

S - Another, G - Wholesale and Retail, H - Transport and Storage, C - Manufacturing, F - Building, I - Accommodation and Catering, J - Information and Communication Activities, A - Agriculture, Forestry, Fishery, E - Water Sector, D - Electricity and Gas, Q - Health and Social Care, M - Research and Technical Activities, $\mathrm{O}-$ Public Administration and Defence)

\section{RESEARCH RESULTS AND DISCUSSION}

Based on the further research (Hafeez et al., 2002, Hafeez \& Abdelmeguid, 2003) many organisations believe that management of their knowledge, skills and competences is the key to their survival in the knowledge economy - in the age of Intellectual Capital. The connection between Diversity Management and Intellectual Capital and also the benefits of diversity and 
its correspondence with all three areas of Intellectual Capital (Human, Structural and Relational Capital) has been proved by a desk research of extant literature. In previous research which was conducted by Richard et al. (2007) the direct positive relationship between knowledge, diversity and business performance was found. They proved that diverse groups of employees possess greater range of knowledge than homogeneous groups. Another connection between diversity and Intellectual capital is provided by Carpenter et. al. (2001) who found that managers with international assignment experience - managers who are influenced by diversity in the way of culture, ethnicity, mental and physical abilities, religion - create more value for their businesses than those without this type of human capital. Following the already conducted research in the area of Diversity (Egerova \& Jirincova, 2014, Egerova, Jirincova, Lancaric \& Savov, 2013) - where the individual organisations clearly showed their interest and positive approach towards the diversity control and using of its benefits - the researchers aimed to find out whether businesses share these ideas and positive approach also in the concept of Intellectual Capital.

The main question was whether the organisations are familiar with the concept of Intellectual Capital and whether they understand its importance in the same level as it was shown for the benefits of Diversity. It can be summarized that the awareness of Intellectual Capital among the questioned businesses is rather higher as the result value of the answers is above the level of 5 based on average values (5,51 in particular). Based on the questionnaire it means "almost completely agree" with the statement. On the other hand, the results regarding Diversity Management are not so positive since $67 \%$ of all the respondents have never heard of this term of Diversity Management. Most of the respondents understand the concept of Diversity and realizes various ways of its use and benefits which are brought. Nevertheless, the notion of Diversity Management was in the period of 2012/2013 fairly unknown (Jirincova, 2013).

With regard to understanding the importance of Intellectual Capital among the respondents a positive part of the result is the reached value of the answers provided by the respondents which again gained the value higher than 5 (5,59 in particular). In case of Diversity Management the respondents also evaluated rather positively its importance and benefits, the average answers correspond with the "almost completely agree" answer. Therefore, the results in the area of understanding Intellectual Capital and Diversity Management can be understood as almost identical. Neither size, nor sector of a business has any statistically significant influence on the respondents' awareness of Intellectual Capital. Examining the arithmetical average values it can be realized a slightly higher awareness of IC by large businesses but this result is statistically irrelevant. In this case it can be stated that regardless size or sector of a business the questioned businesses has certain awareness of the Intellectual Capital concept which opens a space for its further actual use. With regard to understanding the importance of Intellectual Capital among the respondents, the results did not prove any influence of size or sector of the business. Not only did the respondents show a significant level of awareness of Intellectual Capital; moreover, they also claimed their understanding of the importance to manage Intellectual Capital and the importance of Diversity Management. This result is more than positive outcome of the research and it has a significant meaning for the practical use of Intellectual Capital within companies by using of Diversity Management as its supporting tool with the aim to create value and improve business performance. As a suggestion for further research there is a question of which benefits of diversity can be the most efficient for managing of Intellectual Capital and interaction of knowledge within the company. 


\section{CONCLUSION}

Diversity is still considered a new factor of human resource and its phenomenon takes part in modern management and intellectual era thanks to demographic, economics, social or juridical changes. The highest connection between Diversity and Intellectual Capital can be seen in the part of Human Capital. The company's Human Capital, i.e. knowledge, skills and abilities of the workforce, i.e. the employees, are necessary for organizational survival (Barney \& Wright, 1998). Diversity Management is considered in this paper to be the factor which carries the potential to influence the quality of Intellectual Capital in an organisation and therefore its understanding should be on a similar level based on the opinion of the authors. The aim of the paper was to create a theoretical framework for the connection of two actual and modern concepts - the concept of Intellectual Capital and Diversity Management. The empirical part of the paper used the outcomes of two questionnaire surveys which dealt with the topic of Diversity Management and the concept of Intellectual Capital. The main positive outcome of this paper is the confirmation of understanding of the importance to manage Intellectual Capital and the importance of Diversity Management by respondents of both questionnaires - the top managers of various businesses. The outcome of this paper is to consider Diversity Management as a part of Intellectual Capital in further research. The main task for the following research is to find the way of integration of the benefits and components of diversity into particular parts of concepts of Intellectual Capital and its drivers.

Acknowledgement

The research study was created within the project SGS-2014-040 Modern practices in innovation, entrepreneurship and company management, University of West Bohemia in Pilsen.

\section{References}

1. Armstrong, M. (2007). Řizení lidských żdrojü. Nejnovějsí trendy a postupy (10th ed). Praha: Grada Publishing.

2. Barney, J. B., \& Wright, P. M. (1998). On becoming a strategic partner: the role of human resources in gaining competitive advantage. Human Resource Management, 37(1), 31-46. doi: 10.1002/(SICI)1099-050X(199821)37:1\%3C31::AID-HRM4\%3E3.0.CO;2-W

3. Bontis, N. (1999). Managing organizational knowledge by diagnosing intellectual capital: framing and advancing the state of the field. International Journal of Technology Management, 18(5/6/7/8), 433-462. doi:10.1016/B978-8-7506-7475-1.50006-3

4. Bontis, N. \& Cabrita, M.R. (2008). Intellectual capital and business performance in the Portuguese banking industry. Int. J. Technology Management, 43(1/2/3), 212-237. doi: 10.1504/ IJTM.2008.019416

5. Brownlow, Ch. (2004), SPSS Explained. Hove: Routledge.

6. Bureš, V. (2007). Znalostni management a proces jeho zavádèni - priovodce pro praxi (1st ed.). Praha: Grada Publishing.

7. Carpenter, M., Sanders, G., \& Gregersen, H. (2001). Bundling human capital with organizational context: The impact of international assignment experience on multinational firm performance and CEO pay. Academy of Management Journal, 44(3), 493-511. doi: $10.2307 / 3069366$ 
8. Davies, C. A., \& Magowan, J. (2002). An examination of the transfer of intellectual capital across cultures, In. N. Bontis (Ed.), World Congress on Intellectual Capital Readings, pp. 356-373, Boston, MA: Butterworth-Heinemann. doi: 10.1016/B978-0-7506-7475-1.50023-3

9. EC. Continuing the Diversity Journey. (2008). Retrieved June 5, 2015 from: http:// bookshop.europa.eu/en/continuing-the-diversity-journey-pbKE8108424/

10. EC. Diversity Management. (2007). Vz̨élávaci manuál. Retrieved June 5, 2015 from: http:// www.idm-diversity.org/files/EU0708-TrainingManual-cs.pdf

11. EC. The costs and benefits of diversity. (2003). Retrieved June 5, 2015 from: http://www.coe. int $/ \mathrm{t} / \mathrm{dg} 4 /$ cultureheritage/mars/source/resources/references/others/17\%20-\%20Costs $\% 20$ and $\% 20$ Benefits $\% 20$ of $\% 20$ Diversity $\% 20-\% 20$ EU $\% 202003 \% 20$ ExSum.pdf

12. Edvinsson, L., \& Sullivan, P. (1996). Developing a model for managing intellectual capital. European Management Journal, 14(4), 356-364. doi: 10.1016/0263-2373(96)00022-9

13. Egerová, D., Jiřincová, M., Lančarič, D., \& Savov, R. (2013). Applying the concept of diversity management in organizations in the Czech Republic and the Slovak Republic - a research survey. Technological and Economic Development of Economy. LT, 19(2), 350-366, ISSN 2029-4913

14. Egerová, D., \& Jiřincová, M. (2014). Managing workplace diversity - empirical evidence from Czech Republic. Actual Problems of Economics. UA: Kyjev, 7(157), 335 - 342.

15. Esty, Katharine C. (1995). Workplace Diversity. Avon MA: Adams Media.

16. Hafeez, K., Zhang, Y., \& Malak, N. (2002). Core competence for sustainable competitive advantage: A structured methodology for identifying core competence. IEEE Transactions on Engineering Management, 49(1), 28-35. doi: 10.1109/17.98745

17. Hafeez, K., \& Abdelmeguid, H. (2003). Dynamics of Human Resource and Knowledge Management. Journal of the Operational Research Society, 54(2), 153-164. doi: 10.1057/palgrave. jors. 2601513

18. Hope, J., \& Fraser, P. (2013). Beyond Budgeting: how managers can break, free from the annual performance trap. Harvard Business School Press.

19. Hubbard, E. E. (2004). The Manager's Pocket Guide to Diversity Management. Amherst: HRD Press.

20. Hubbard, E. E. (2011). The diversity scorecard. New York: Taylor \& Francis.

21. Hudson, W. (1993). Intellectual capital: How to Build it, Enhance it, Use it. NY: John Wiley \& Sons.

22. Intellectual Capital Reporting. (2014). StrategyBuilders.eu. Retrieved June 5, 2015 from: http://www.strategybuilders.eu/news/intellectual-capital-reporting/

23. Jiřincová, M. (2011). Diverzita v ČR a její reflexe pro podniky a zaměstnanost. Trendy v podnikání. ZČU v Plzni, 1(1), 5 - 10.

24. Jiřincová, M. (2013) Potential Future Managers and Their Opinion on the Issue of Diversity, Inclusion and Their Possible Use in Management. Journal of Competitiveness, 5(2), 37-50. doi:10.7441/joc.2013.02.03 
25. Kaplan, R. S. \& Norton, D. P. (2004). Strategy maps: converting intangible assets into tangible outcomes. Boston: Harvard Business School Publishing Corporation.

26. Krechovská, M. (2014, October). Business Performance Management Considering Intellectual Capital. In Proceedings of the 6th European Conference on Intellectual Capital: ECIC 2014. (pp. 85-90). Academic Conferences Limited.

27. Lesser, E. R. (2009). Knowledge and Social Capital. Routledge.

28. Marr, B. (2005). Perspectives on Intellectual Capital: Multidisciplinary Insights into Management, Measurement and Reporting. Oxford: Butterworth-Heinemann.

29. Navarro, J. L. A., Ruiz, V. R. L, \& Pena, D. N. (2013). A theoretical intellectual capital model applied to cities. Amfiteatru Economic, 15 (34), 455-468.

30. Prochazkova, P. T. (2014). Entrepreneurship and Incubation Activities in Praxis: Benchmarking Observations, 3rd International Business Information Management Association Conference on Visio 2020: Sustainable Growth, Economic Development, and Global Competitiveness. Norristown, pp. 2140-2148.

31. Prochazkova, P. T. (2012). Business incubator as a tool of support of small and medium size enterprises/Podnikatelsky inkubator jako nastroj podpory maleho a stredniho podnikani. E+ M Ekonomie a Management, 15(7), 91-108.

32. Richard, O. C., Murthi, B. P. S., \& Ismail, K. (2007). The Impact of Racial Diversity on Intermediate and Long-Term Performace: The Moderating Role of Environmental Context. Strategic Management Journal, 28(12), 1213-1233. doi: 10.1002/smj.633

33. Stewart, T. A. (2010). Intellectual Capital: The new wealth of organization. New York: Random House LLC.

34. Sveiby, K. E. (1997). The New Organizational Wealth: Managing \& Measuring Knowledge-based Assets. San Francisco: Berrett-Koehler Publishers, 1997.

35. Thiederman, S. (2008). Making Diversity Work. New York: Kaplan, Inc.

36. Thomas, R. Jr. (2006) Building on the promise of diversity: how we can move to the next level in our workplaces, our communities, and our society. New York: AMACOM.

\section{Contact information}

Ing. Eva Jelinková

University of West Bohemia in Pilsen, Faculty of Economics

Husova 11, Plzeň 306 14, Czech Republic

E-mail:ejelinko@kpm.zcu.cz.

Ing. Milena Jirincová, Ph.D.

University of West Bohemia in Pilsen, Faculty of Economics

Husova 11, Plzeň 306 14, Czech Republic

E-mail:milenaj@kpm.zcu.cr. 